\begin{tabular}{|c|c|}
\hline Title & Development of suitable product recovery systems of continuous hy brid jig for plastic-plastic separation \\
\hline Author(s) & $\begin{array}{l}\text { Ito, Mayumi; Saito, A yumu; Murase, Nana; Phengsaart, Theeray ut; Kimura, Shoko; Tabelin, Carlito Baltazar; } \\
\text { Hiroy oshi, Naoki }\end{array}$ \\
\hline Citation & $\begin{array}{l}\text { Minerals engineering, } 141,105839 \\
\text { https://doi.org/10.1016/.mineng.2019.105839 }\end{array}$ \\
\hline Issue Date & $2019-09$ \\
\hline Doc URL & http:/hdl .handle.net/2115/82578 \\
\hline Rights & $\begin{array}{l}\text { () 2019. This manuscript version is made available under the CC-BY-NC-ND } 4.0 \text { license } \\
\mathrm{http}: / / \text { reativecommons.org/icenses/by-nc-nd/4.0/ }\end{array}$ \\
\hline Rights(URL) & http://creativecommons.org/icenses/by-nc-nd/4.0/ \\
\hline Type & article (author version) \\
\hline File Information & Revised manuscript.pdf \\
\hline
\end{tabular}

Instructions for use 


\title{
Development of suitable product recovery systems of continuous hybrid jig for plastic-plastic separation
}

Mayumi Ito ${ }^{\mathrm{a},}$, Ayumu Saito ${ }^{\mathrm{b}}$, Nana Murase ${ }^{\mathrm{b}}$, Theerayut Phengsaart ${ }^{\mathrm{b}}$, Shoko Kimura ${ }^{\mathrm{c}}$, Carlito Baltazar Tabelin ${ }^{\mathrm{a}, \mathrm{d}}$, Naoki Hiroyoshi ${ }^{\mathrm{a}}$

a Division of Sustainable Resources Engineering, Faculty of Engineering, Hokkaido University, Kita 13, Nishi 8, Kita-ku, Sapporo 060-8628, Japan

b Division of Sustainable Resources Engineering, Graduate School of Engineering, Hokkaido University, Kita 13, Nishi 8, Kita-ku, Sapporo 060-8628, Japan

${ }^{\mathrm{c}}$ Cooperative Program for Resources Engineering, Graduate School of Engineering, Hokkaido University, Kita 13, Nishi 8, Kita-ku, Sapporo 060-8628, Japan

${ }^{\mathrm{d}}$ School of Minerals and Energy Resources Engineering, The University of New South Wales, Sydney, NSW 2052, Australia

* Corresponding author: itomayu@eng.hokudai.ac.jp

\begin{abstract}
A modified jig called the hybrid jig was recently developed to separate mixed-plastics with similar specific gravities effectively using the concepts of bubble attachment, surface wettability and gravity separation. This method was effective in a batch-type jig setup, but when applied to a continuous-type jig setup, the efficiency of the process dramatically decreased. This drop in efficiency was attributed to the unintended negative effects of air bubbles on separation especially close to the screw-type extractor at the product end though this type of product recovery system was successfully applied to the RETAC and reverse jigs. To address this problem, a better product recovery system for continuoustype hybrid jig is proposed in this study, and the effects of air injection rate at different positions of the hybrid jig separation chamber were evaluated. The results showed that fluidization behavior of particles in the hybrid jig was influenced by not only water pulsation but also the rising motion of air bubbles. To improve the purity of heavy materials in the bottom layer products, two product recovery systems are proposed: (1) a screw-type extractor with one "separating" single-screen, and (2) a screw-type extractor with modified air injection and water pulsation (i.e., upward flow period was shortened).
\end{abstract}

Keywords: Recycling; jig; hybrid jig; continuous jig; plastic 


\section{Introduction}

Jig separation is a gravity separation technique that separates particles based on differences in their specific gravities (SG). In a conventional jig, water pulsation is comprised of an upward period that facilitates particle bed expansion (i.e., fluidization) and a downward flow period, which allows for the settling down of particles under the influence of gravity (Wills and Napier-Munn, 2006). Repetition of water pulsation in jig separation causes stratification based on particle settling velocity differences. Jigs typically operate under wet conditions and are widely used in mineral processing especially for coal cleaning because they are simple to operate, low cost, and have higher efficiency than dry-type separation techniques (Boylu et al., 2015; Gupta and Yan, 2006; Wills and Napier-Munn, 2006). Because of these inherent advantages over other processing techniques, jig separation has recently been modified for application in the recycling of various types of wastes (Hori et al., 2009a, b; Jeon et al., 2019; Phengsaart et al., 2018; Tsunekawa et al., 2005).

Plastics are among the most versatile materials known to man. The total global production of this material has grown from around 1.5 million tons in 1950 to 348 million tons in 2017 . The world consumption has also been increasing yearly at a rate of $5 \%$ with the largest increase reported in Asia especially in China, which is the world leader in terms of plastic production due to the country's low production costs (PlasticsEurope, 2018; Statista, 2019). One property of plastics that made them important is their ability to be modified and engineered to suit various applications at a fraction of the cost of more traditional materials. Plastics are found in cars, electronics, home appliances and packaging materials to name a few. Because of this, plastics have dominated the bulk of wastes generated by our modern society and recycling these wastes is not only good for resources sustainability but also to the environment.

In Japan, the generation of waste plastics have gradually decreased for the past 20 years because of the enactment of recycling laws for "containers and packaging" and "home appliances" (i.e., air conditioners, televisions, refrigerators, and washing machines) in 1995 and 1998, respectively (Ministry of the Environment of Japan, 2014; PlasticsEurope, 2015; Plastic Waste Management Institute of Japan, 2019). In 2016, for example, about 9 million tons (roughly $84 \%$ of the total amount of plastic wastes) was recycled in Japan, 58 and $23 \%$ of which went to thermal and material recycling, respectively while the remaining $19 \%$ were disposed of in landfills. Thermal recycling is a process whereby plastics are recovered and utilized as fuel for power generation, an approach that is more widely used to manage plastic wastes than material recycling (Choi et al., 2018). Because plastics are primarily composed of carbon, they are good 
sources of energy for electric power generation plants. Some plastics like polyvinyl chloride (PVC), however, are unsuitable for thermal recycling because they contain chloride that have adverse effects to the refractory materials used in boilers and should be separated prior to thermal recycling (Kikuchi et al., 2008, Kuwayama et al., 2011, Phengsaart et al., 2018). Although more profitable and sustainable, material recycling of plastic wastes remains limited because of the huge challenges and difficulties of efficiently separating the various types of plastics they contain to generate products with purities of over $99 \%$. This means that plastic-plastic separation techniques should be developed or improved for both thermal and material recycling applications (Choi et al., 2018). Another potentially promising application of improved gravity separation techniques is in the recovery of printed circuit boards (PCBs) found in plastic wastes that contain valuable metals like gold and copper (Jeon et al., 2018a, 2018b, 2019).

Several studies reported that the separation of mixed-plastics into their individual components using traditional jigs employed in mineral processing was possible (Hori et al., 2009a, b; Kuwayama et al., 2011; Pita and Castilho, 2016; Tsunekawa et al., 2005). Because traditional jigs are designed for ores, however, their direct application to mixed-plastic wastes having lower SGs caused unpredictable fluidization behavior during separation resulting in very low separation efficiency (Ito et al., 2010). The RETAC jig (R\&E, Co., Ltd., Japan), a modified Takakuwa Air Chamber Under Bed (TACUB) jig (commercially known as BATAC jig), was developed by the authors to address this issue and specifically separate materials with SGs very close to that of water like plastics. The strength of this new jig lies in its ability for precision control of water pulsation and has been shown to produce sharp separation (Hori et al., 2009a, Ito et al., 2010; Tsunekawa et al., 2005). For example, the RETAC jig was applied to separate various plastics (e.g., polystyrene (PS), acrylonitrile butadiene styrene (ABS), and polyethylene terephthalate (PET)) from copy machines (Tsunekawa et al., 2005). For plastics having lower SG than water (e.g., polyolefin), the Reverse jig, a modified RETAC jig with a top screen could be used. Like the conventional RETAC jig, the reverse jig separates various plastics lighter than water by stratification based on their SGs. In the separation chamber, particles move up and down underneath the top screen and stratification occurs because of differences in particle's levitation velocity. This type of jig was successfully applied to separate polypropylene (PP) and high-density polyethylene (HDPE) from waste containers (Ito et al., 2010).

More recently, the principles of gravity separation and flotation has been combined to develop a new technique called the hybrid jig. The hybrid jig is modified version of the RETAC jig that can separate materials having similar SG but different 
surface wettability. In hybrid jig separation, aeration tubes installed inside the separation chamber beneath the particle bed to generate air bubbles (Fig. 1). When bubbles attach to particles, the "apparent" SG of particles with attached bubbles becomes lower than those particles without any attached bubbles. Because of this SG difference induced by bubble attachment, particles with bubbles could be recovered as top layer products via jigging stratification (Hori et al., 2009b). The batch-type RETAC, reverse, and hybrid jigs have already been developed while for the continuous-type setup, only the RETAC and reverse jigs had been realized (Ito et al., 2010, Tsunekawa et al., 2012, Hori et al., 2009b).

For the RETAC jig, the authors developed a product recovery system based on a screw-type extractor (Tsunekawa et al., 2012). Although effective for the RETAC jig, the screw-type extractor system could not be used to recover bottom products during hybrid jig separation because of some unintended negative effects of the bubbles. In this paper, better product recovery systems for continuous-type hybrid jig are proposed, and the effects of air injection rate at different positions of the separation chamber were evaluated.

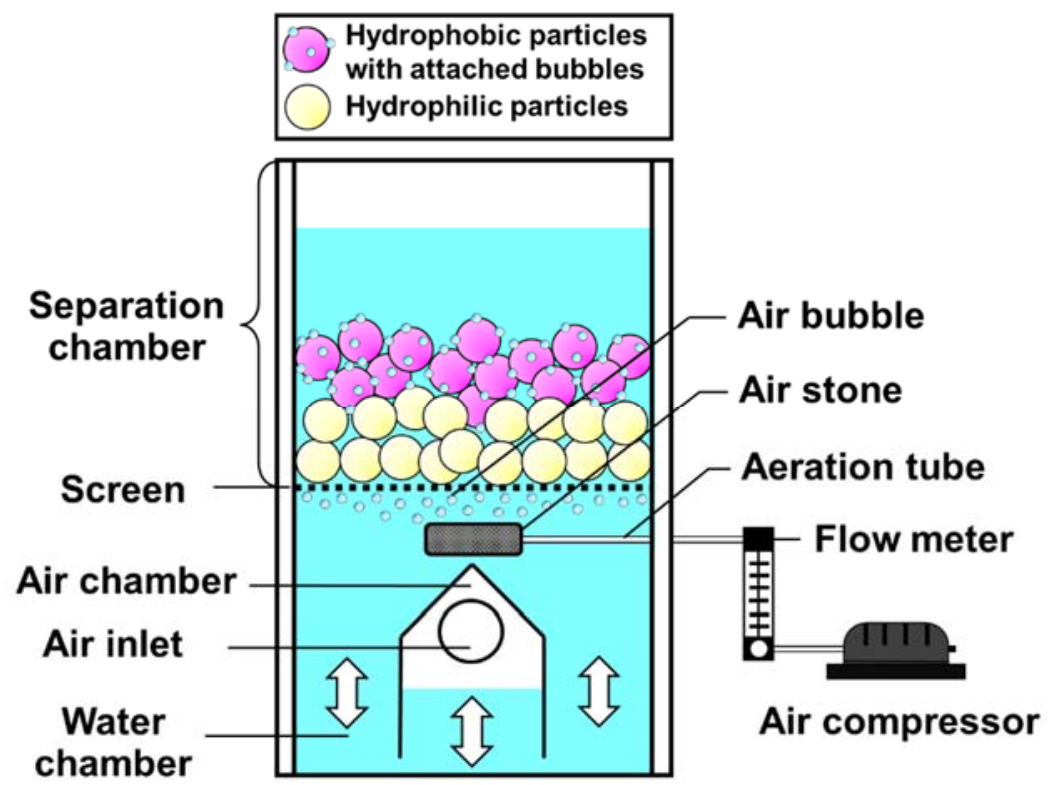

Fig. 1. A schematic illustration of the batch-type hybrid jig. 


\section{Materials and methods}

\subsection{Plastic samples}

Polyethylene terephthalate (PET) and polyvinylchloride (PVC) were used in this study and brief descriptions of their properties are listed in Table 1.

Table 1. Brief descriptions of the plastic samples used in this study.

\begin{tabular}{llll}
\hline Samples & Abbreviation & $\begin{array}{l}\text { Specific gravity } \\
\text { (SG) }\end{array}$ & $\begin{array}{l}\text { Contact angle } \\
\left.\text { in water } \mathbf{~}^{\mathbf{0}}\right)\end{array}$ \\
\hline $\begin{array}{l}\text { Crushed PET boards 2 mm } \\
\text { thickness (2-8 mm) }\end{array}$ & PET & 1.31 & 96 \\
$\begin{array}{l}\text { PVC pellets } \\
(2 \times 4 \times 4 \mathrm{~mm})\end{array}$ & PVC & 1.38 & 96 \\
\hline
\end{tabular}

\section{$2.2 \quad$ Jig separation tests}

\subsubsection{Batch-type jig experiments with and without air injection}

Batch-type jig separation experiments (jig separation chamber: 145-mm long, 155-mm wide, and 320-mm high from the bottom screen) (Fig. 1) were carried out with and without air injection. The experiments were conducted under the following conditions: water volume of $18 \mathrm{~L}$, displacement of $10 \mathrm{~mm}$, water pulsation frequency of 30 cycles/min, $20 \mathrm{ppm}$ of methyl isobutyl carbinol (MIBC, Wako Pure Chemical Industries Ltd., Japan) to stabilize bubble formation in solution, air injection rate of 0 or $300 \mathrm{~mL} / \mathrm{min}$, and separation time of $3 \mathrm{~min}$. After each experiment, the products were divided into six layers from the top (20-mm intervals), collected using a vacuum sampling system, and then separated by hand-picking to determine the purity of jig products.

\subsubsection{Continuous-type hybrid jig experiments}

A continuous-type hybrid jig with a separation chamber 445-mm long, 150-mm wide, and 550-mm high from the bottom screen (Fig. 2) was used. In commercial-scale coal cleaning operations using the BATAC jig, a gate-type system is used to recover the bottom product containing high SG materials such as rocks that can be removed easily via gravity (MBE Coal \& Minerals Technology GMBH, 2011). This type of gravity-based recovery system is, however, unsuitable for the RETAC jig because it treats plastics having low SGs and low settling velocities. Because of this, mechanical extractors (e.g., screw-type extractor) are preferred in continuous-type RETAC jig to recover the bottom products at an adjustable rate while the top products are recovered from the overflow launder.

Continuous hybrid jig separation experiments were conducted under the following conditions: water volume of $55 \mathrm{~L}$, displacement of $10 \mathrm{~mm}$, water pulsation 
frequency of $30 \mathrm{cycles} / \mathrm{min}$, and $20 \mathrm{ppm}$ of MIBC. Air injection rates at each air stone (Table 2) was selected based on the previous works of Hori and co-authors (2009a, b). Particle motion during the upward and downward flow periods during continuous-type hybrid jig separation were recorded by a high-speed video camera and analyzed by particles image velocimetry (Flownizer2D, Ditect Co. Ltd., Japan) using particle tracking velocimetry (PTV) method.

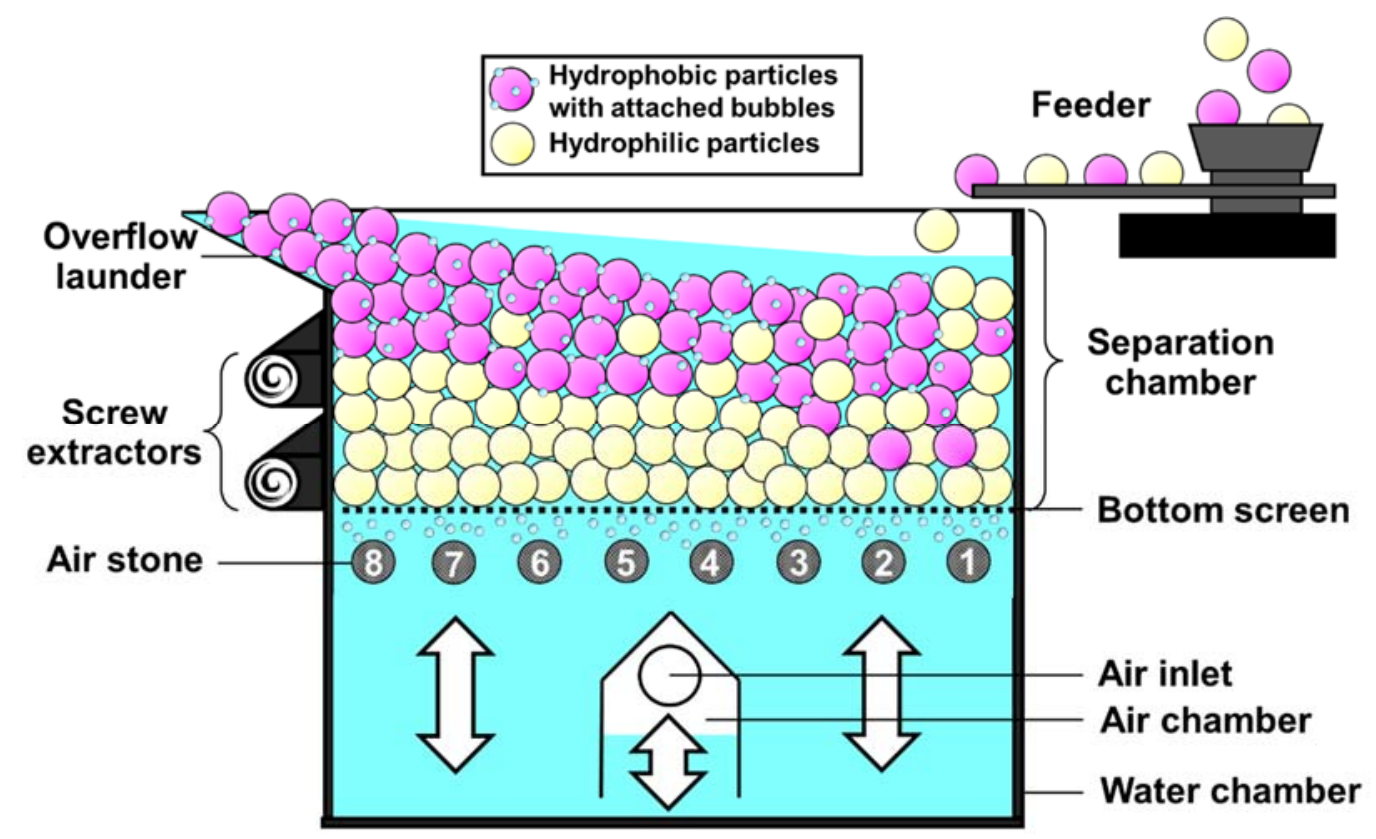

Fig. 2. A schematic illustration of the continuous-type hybrid jig.

Table 2. Air injection rates at each air stone $(\mathrm{mL} / \mathrm{min})$

\begin{tabular}{lllllllll}
\hline Air stone & $\mathbf{1}$ & $\mathbf{2}$ & $\mathbf{3}$ & $\mathbf{4}$ & $\mathbf{5}$ & $\mathbf{6}$ & $\mathbf{7}$ & $\mathbf{8}$ \\
\hline Condition 1 & 800 & 800 & 800 & 800 & 800 & 800 & 800 & 800 \\
Condition 2 & 600 & 600 & 600 & 500 & 500 & 500 & 500 & 500 \\
Condition 3 & 700 & 700 & 700 & 700 & 700 & 700 & 700 & - \\
\hline
\end{tabular}

Note: "-" means no air injection. 


\section{Results and discussion}

\subsection{Effects of air injection on jig separation}

As preliminary experiments, batch-type jig tests (145-mm long, 155-mm wide, and 320-mm high from bottom screen) with and without air injection were carried out. Fig. 3 shows better separation efficiency with air injection (hybrid jig) than that without air injection. This means that hybrid jig can separate PVC and PET by differences of surface wettability and SG, which are in line with the previous results of Hori et al. (2009b) using different plastics. Without air injection, PET (SG of 1.31) was recovered in the top layers and PVC (SG of 1.38) was recovered in the bottom layers. In comparison, PVC was recovered in the top layers after hybrid jig separation because PVC is more hydrophobic than PET and its "apparent" SG became lower than that of PET due to bubble attachment.

(a) Batch-type RETAC jig w/o bubble injection

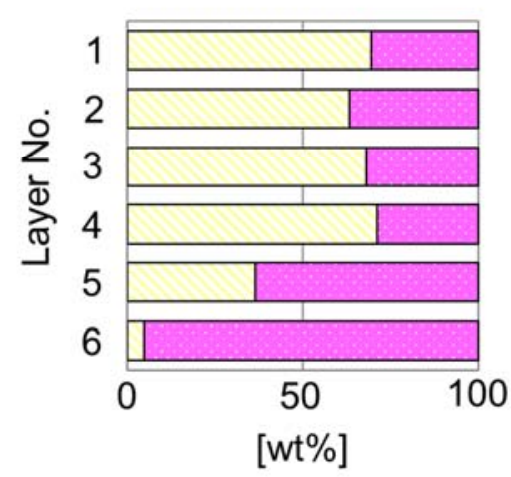

(b) Batch-type hybrid jig w/ bubble injection $(300 \mathrm{~mL} / \mathrm{min})$

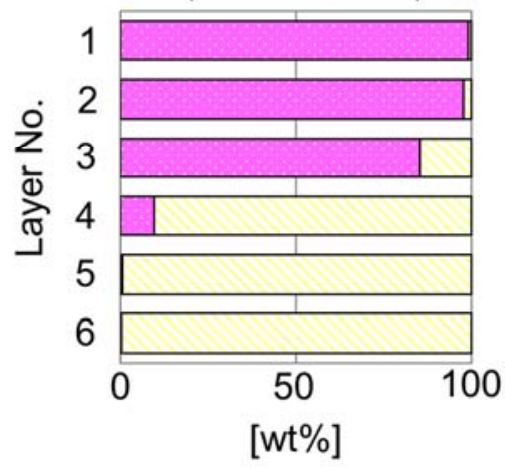

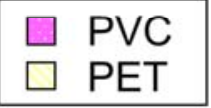

Fig. 3. Distributions of PET and PVC in each layer after the batch-type experiments using (a) the RETAC jig, and (b) the hybrid jig.

\subsection{Continuous hybrid jig separation using separating screens with two and three product recovery system}

In the previous section, high purity $(>99 \%)$ in top and bottom layer products was obtained by batch-type hybrid jig. In this section, continuous-type hybrid jig was developed to recover the top and bottom layer products with high purity (Fig. 3b). As noted previously, the authors developed a product recovery system using a screw-type extractor for the RETAC jig. When used in the hybrid jig, however, this type of extractor system became inefficient because air bubble introduction resulted in the fluidization of particle bed close to the screw-type extractor. To prevent fluidization of particle bed at 
the product-end, two separating screens, top/middle (length of $180 \mathrm{~mm}$ and a distance of $150 \mathrm{~mm}$ from the bottom screen) and middle/bottom (length of $140 \mathrm{~mm}$ and a distance of $70 \mathrm{~mm}$ from the bottom screen), were installed (Fig. 4). Fig. 5 shows the purity of PVC in top layer products and PET in the bottom layer products of continuous-type hybrid jig with and without the separating screens using two- and three-product recovery systems (Fig. 4) with condition 1 as air injection rates (Table 2).

The purity of PVC in the top layer products were similar under all conditions and high purity $(>96 \%)$ were obtained using the overflow launder. In contrast, the bottom layer products could not be recovered by the screw extractors without any separating screen because bubbles caused fluidization of the particle bed at the product end. In these experiments, the bottom and middle layer products were recovered manually after jig operation because even though the screw extractors were in operation, jig products could not be recovered. The purity of PET in bottom layer products using the two-product recovery system without separating screen (Fig. 5a) was low (58\%), indicating that modification is needed to improve the purity of bottom layer products. The purity of PET in bottom layer products using the three-product recovery system without separating screen (Fig. 5b) was even lower (47\%) than that of the two-product recovery system (Fig. 5a). This lower purity may be attributed to the mixing of materials due to the horizontal flow of water induced by the rotating motion of the screw-type extractor. In the threeproduct recovery system (with two screw extractors) (Fig. 4b), the particles could move faster in the horizontal direction due to water flow from the feed side to product-end of the jig (Fig. 4a). This faster movement caused mixing of materials in the three-product recovery system, resulting in the low purity of bottom layer products. To prevent the movement of particles at the product-end, two separating screens (top/middle: length of $180 \mathrm{~mm}$ and a distance of $150 \mathrm{~mm}$ from the bottom screen and middle/bottom: length of $140 \mathrm{~mm}$ and a distance of $70 \mathrm{~mm}$ from the bottom screen) were installed (Fig. 4). Using this product recovery setup, the bottom layer products could be recovered by the screwtype extractor but purity of PET in the bottom layer products remained low (Fig. 5c). 
(a)

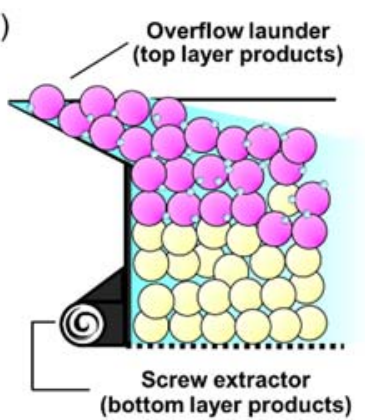

(b)

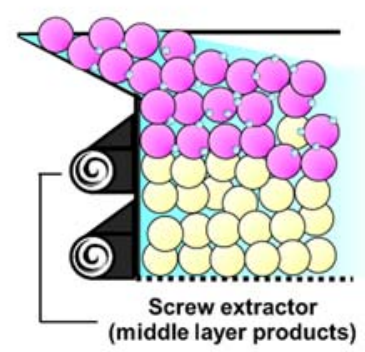

(c)

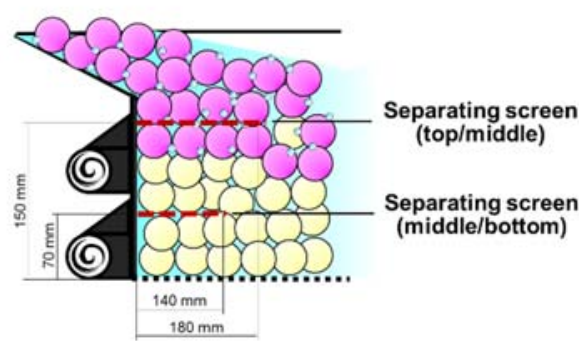

Fig. 4. Product recovery system of continuous-type hybrid jig: (a) two-product recovery system without separating screen, (b) three-product recovery system without separating screen, and (c) three-product recovery system with two separating screens (top/middle and middle/bottom).
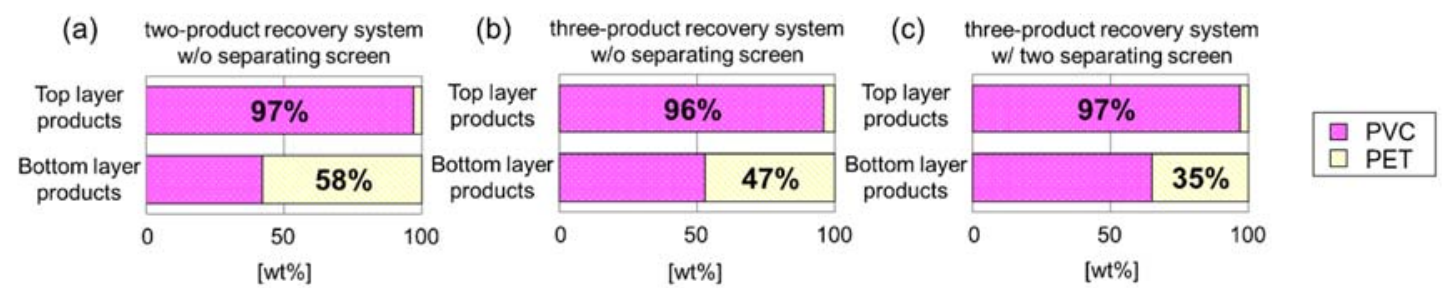

Fig. 5. Distributions of PET and PVC in top and bottom layer products after the continuous-type hybrid jig experiments of (a) two-product recovery system without separating screen, (b) three-product recovery system without separating screen, and (c) three-product recovery system with two separating screens (top/middle and middle/bottom).

Table 3. Yield and recovery of top and bottom layer products after the continuous-type hybrid jig experiments of (a) two-product recovery system without separating screen, (b) three-product recovery system without separating screen, and (c) three-product recovery system with two separating screens (top/middle and middle/bottom).

\begin{tabular}{lcccc}
\hline Product recovery system & \multicolumn{3}{c}{ Top layer product } & \multicolumn{2}{c}{ Bottom layer product } \\
\cline { 2 - 5 } & $\begin{array}{c}\text { Yield } \\
(\%)\end{array}$ & $\begin{array}{c}\text { Recovery of PVC } \\
\mathbf{( \% )}\end{array}$ & $\begin{array}{c}\text { Yield } \\
\mathbf{( \% )}\end{array}$ & $\begin{array}{c}\text { Recovery of PET } \\
\text { (\%) }\end{array}$ \\
\hline $\begin{array}{l}\text { (a) two-product w/o } \\
\text { separating screen }\end{array}$ & 15 & 29 & 85 & 99 \\
$\begin{array}{l}\text { (b) three-product w/o } \\
\text { 1 separating screen } \\
\text { (c) three-product w/ }\end{array}$ & 22 & 42 & 39 & 37 \\
two separating screens & 26 & 50 & 37 & 26 \\
\hline
\end{tabular}




\subsection{Modification of product recovery system for the continuous hybrid jig}

To improve the purity of PET in bottom layer products, the following modifications were applied in the three-product recovery system: (i) single screen system, (ii) two screen system with air injection modification, and (iii) two screen system with air injection and water pulsation modifications.

\subsubsection{Single screen system}

Since the purity of PVC in top layer products with the three-product recovery system with two separating screens was high (97\%), removal of the separating screen (top/middle) was tested. The purity of PVC in top layer products improved to $99 \%$ while that of PET in the bottom layer products increased from 35 to $85 \%$. Better separation occurred likely because removal of the separating screen (top/middle) allowed particles in the top and middle layer positions to move more freely and stratify. In practical plants, this middle layer products are returned to the feed, so high purity of top and bottom layer products could be obtained.

\subsubsection{Air injection modification}

By visual inspection, fluidization of particle bed due to the rising motion of air bubbles caused the unintended mixing of materials. In the RETAC jig (without air injection) fluidization occurs due to water pulsation only (Hori et al., 2009a), but in the hybrid jig, fluidization was caused by both water pulsation and the rising motion of air bubbles. This means that one possible way to limit fluidization is to reduce air injection rate (Table 2; condition 2). Fig. 6 shows that purity of PET in the bottom layer products of (b) condition 2 (27\%) decreased from (a) condition 1 (35\%). This low purity was caused by incomplete separation due to imperfect fluidization. These results indicate that in hybrid jig separation, both water pulsation and air injection rates are important, so control of fluidization behavior close to the product end is required.

\subsubsection{Air injection modification with modified water pulsation}

Firstly, modification of water pulsation was applied. Our previous study reported that optimum water rising velocity can be estimated using the SG of heavy material (Hori et al., 2009a). For plastic mixtures containing materials with SG of 1.3 and particle bed thickness of $200 \mathrm{~mm}$, the optimum water rising velocity was around $25-30 \mathrm{~mm} / \mathrm{s}$ based on previous fluidization experiments (Hori et al., 2009a). In previous sections (3.1, 3.2, $3.3 .1,3.3 .2$ ), the water rising velocity was set to $20 \mathrm{~mm} / \mathrm{s}$ (displacement of $10 \mathrm{~mm}$ ), which means that fluidization to obtain good separation was not enough. Moreover, the 
introduction of bubbles not only changed the SG of hydrophobic particles but also altered the movements of particles, both of which made the fluidization behavior of particle bed in a hybrid jig more complicated.

To investigate this phenomenon further, a continuous-type hybrid jig experiment with $40 \mathrm{~mm} / \mathrm{s}$ water rising velocity (displacement of $20 \mathrm{~mm}$ ) was carried out. By visual observation, the particle bed of bottom product was looser especially at air stone no. 8 (Fig. 2), which made the recovery using the screw-type extractor difficult near the product-end. Fig. 7a shows the flow velocities of particles during the upward flow (Fig. 7a-1) and downward flow (Fig. 7a-2) periods of continuous-type hybrid jig separation using particle image velocimetry (Flownizer2D). The results showed that during the upward flow period, particles moved back to the feed direction in the presence of a separating screen (Fig. 7a-1). When the separating screen was removed, pressure exerted by the upper part of the particle bed limited its fluidization. This means that particle movement back to the feed direction in the presence of the separating screen was because of the absence of pressure from the upper part of the particle bed, which made fluidization easier due to the upward flow of water and bubbles. During the downward flow period, the particles moved to the screw-type extractor and were recovered as bottom layer products.

Based on these results, fluidization was controlled by reducing the upward flow period (Fig. 8), increasing the water rising velocity (from 20 to $30 \mathrm{~mm} / \mathrm{s}$ (displacement of $10 \mathrm{~mm}$ ), and removing air injection at air stone no. 8 (Table 2; condition 3). In addition, the downward flow period was extended to increase the recovery rate (Fig. 8). The results showed that purities of bottom layer products increased up to $85 \%$ (Fig. 6c). Moreover, particle image velocimetry results showed that during the upward flow period, water moved up mostly in the vertical direction (Fig. 7b-1) rather than towards the feed direction while during the downward flow period, water moved towards the screw-type extractor (Fig. 7b-2). These results suggest that modification of water pulsation and bubble generation distribution changed the water flow regimes that improved separation efficiency.

Based on these results, a single-screen system (Fig. 6a) or two screen system with air injection and water pulsation modifications (Fig. 6c) could both be applied in hybrid jig separation to improve the purity of heavy materials in the bottom layer products of low SG materials (i.e., plastics) in recycling plants. 
(a)

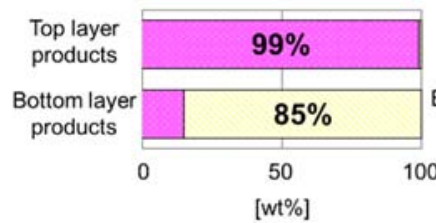

(b)

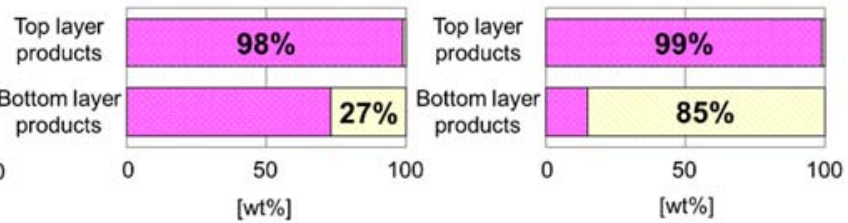

Fig. 6. Distributions of PET and PVC in top and bottom layer products after the continuous hybrid jig experiments of (a) three-product recovery system with single separating screen (middle/bottom) (air injection rate of condition 1 (Table 2)), (b) threeproduct recovery system with two separating screens (top/middle and middle/bottom) (air injection rate of condition 2 (Table 2)), and (c) three-product recovery system with two separating screens (top/middle and middle/bottom) (air injection rate of condition 3 (Table 2)) (Modified water pulsation).

Table 4. Yield and recovery of top and bottom layer products after the continuous-type hybrid jig experiments of (a) three-product recovery system with single separating screen (middle/bottom) (air injection rate of condition 1 (Table 2)), (b) three-product recovery system with two separating screens (top/middle and middle/bottom) (air injection rate of condition 2 (Table 2)), and (c) three-product recovery system with two separating screens (top/middle and middle/bottom) (air injection rate of condition 3 (Table 2)) (Modified water pulsation).

\begin{tabular}{|c|c|c|c|c|}
\hline \multirow[t]{2}{*}{ Product recovery system } & \multicolumn{2}{|c|}{ Top layer product } & \multicolumn{2}{|c|}{ Bottom layer product } \\
\hline & $\begin{array}{l}\text { Yield } \\
(\%)\end{array}$ & $\begin{array}{c}\text { Recovery of PVC } \\
(\%)\end{array}$ & $\begin{array}{l}\text { Yield } \\
(\%)\end{array}$ & $\begin{array}{c}\text { Recovery of PET } \\
(\%)\end{array}$ \\
\hline (a) three-product & 27 & 53 & 36 & 61 \\
\hline $\begin{array}{l}\text { w/ a separating screen } \\
\text { (condition } 1 \text { ) }\end{array}$ & & & & \\
\hline (b) three-product & 25 & 49 & 38 & 21 \\
\hline $\begin{array}{l}\text { w/ two separating screens } \\
\text { (condition } 2 \text { ) }\end{array}$ & & & & \\
\hline (c) three-product & 26 & 51 & 37 & 63 \\
\hline $\begin{array}{l}\text { w/ two separating screens } \\
\text { (condition } 3 \text { ) }\end{array}$ & & & & \\
\hline using modified water & & & & \\
\hline pulsation & & & & \\
\hline
\end{tabular}




\section{$(\mathrm{a}-1)$}

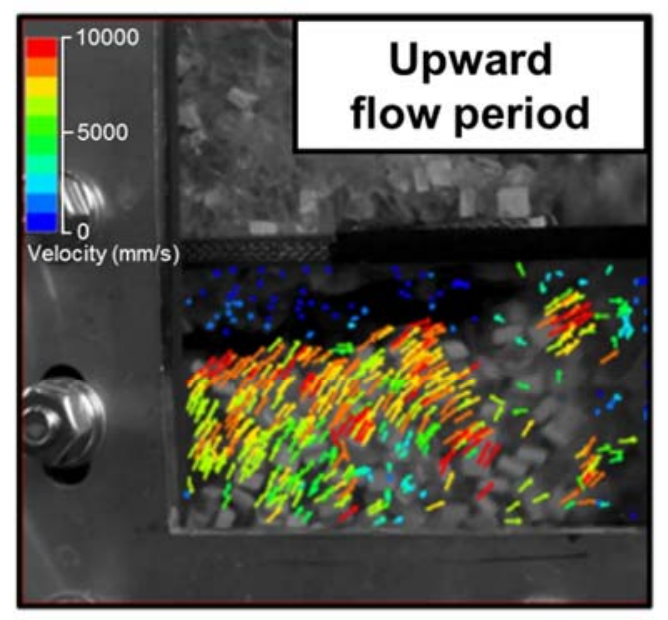

$(b-1)$

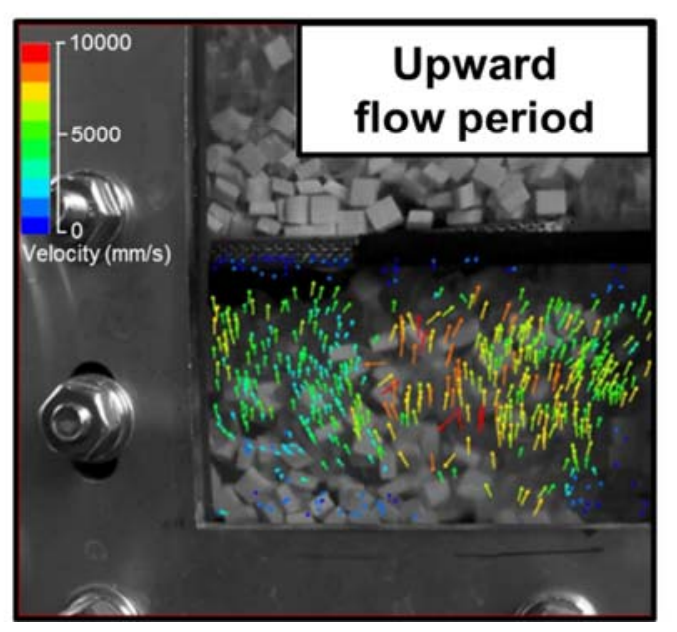

(a-2)

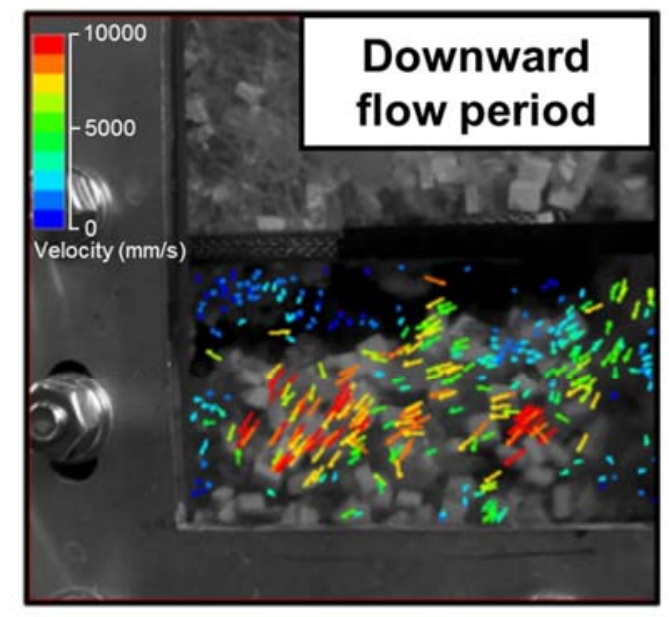

$(b-2)$

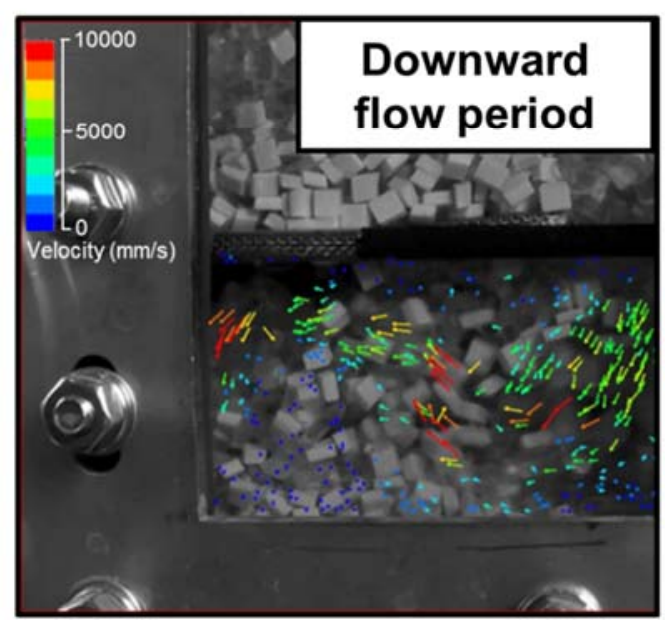

Fig. 7 Particle flow velocities during continuous-type ybrid jig separations with original waveform of water pulsation: (a-1) upward flow period, and (a-2) downward flow period, and with modified water pulsation (optimum condition): (b-1) upward flow period, and (b-2) downward flow period. 


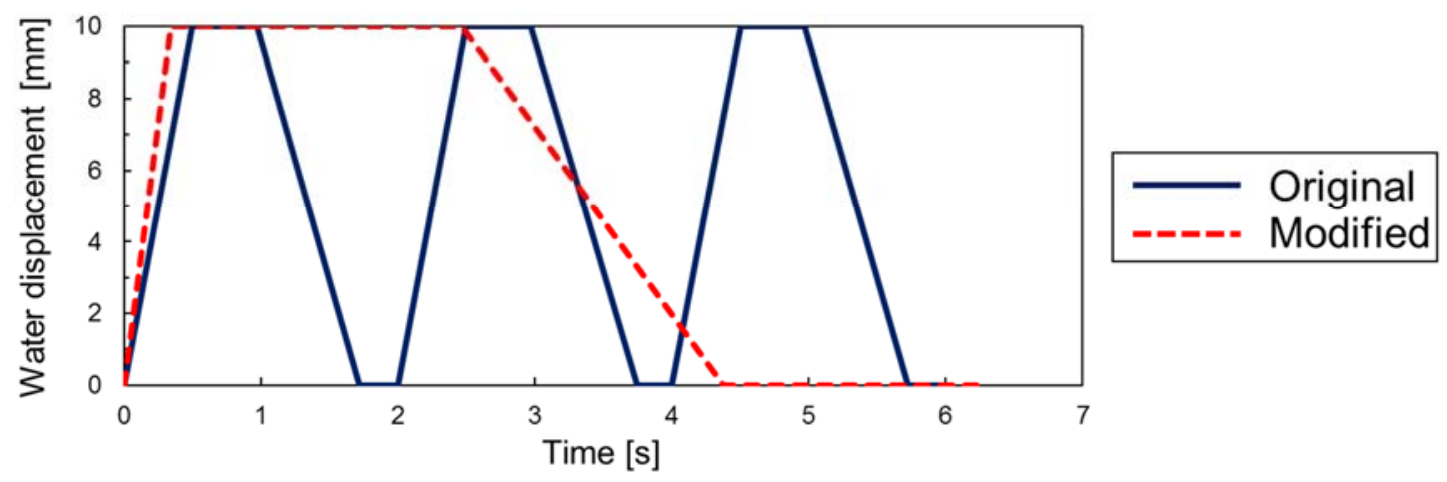

Fig. 8. Original and modified water pulsation waveforms.

\section{Conclusions}

This paper introduced the continuous-type hybrid jig and proposed suitable product recovery systems for plastic-plastic separation. The findings of this study are summarized as follows:

- The separation efficiency of batch-type RETAC jig for mixed-plastics of similar SGs was dramatically improved with air injection (hybrid jig).

- A continuous-type hybrid jig separation using a two-product recovery system with separating screens was better than that of a three-product recovery system.

- During hybrid jig separation, fluidization behavior of the particle bed was influenced by both the water pulsation and rising motion of air bubbles.

- Using two product recovery systems, the separation efficiency of the continuoustype hybrid jig was improved using a single separating screen with air injection and water pulsation modifications (i.e., upward flow period was shortened).

\section{Acknowledgments}

The authors wish to thank Dr. Kristian Edmund Waters and the anonymous reviewers for their valuable inputs to this paper.

\section{References}

Boylu, F., Cinku, K., Cetinel, T., Karakas, F., Guven, O., Karaagaclioglu, I.E., Celik, M.S., 2015. Effect of coal moisture on the treatment of a lignitic coal through a semi-pilot scale pneumatic stratification jig. Int. J. Coal Prep. Util. 35, 143-153. https://doi.org/10.1080/19392699.2015.1005743 
Choi, C., Choi, H.J., Rhee S.W., 2018. Current status and improvements on management of plastic waste in Korea, J. Korean Inst. Resources Recycling. 27, 3-15. https://doi.org/10.7844/kirr.2018.27.4.3

Gupta, A., Yan, D.S., 2006. Mineral Processing Design and Operation - An Introduction, Perth, Australia.

Hori, K., Tsunekawa, Hiroyoshi, N., Ito, M., 2009a. Optimum water pulsation of jig separation for crushed plastic particles. Int. J. Miner. Process. 92, 103-108. https://doi.org/10.1016/j.minpro.2009.01.001.

Hori, K., Tsunekawa, M., Ueda, M., Hiroyoshi, N., Ito, M., Okada, H., 2009b. Development of a new gravity separator for plastics -a Hybrid-jig-. Mater. Trans. 50, 2884-2847. https://doi.org/10.2320/matertrans.M-M2009825.

Ito, M., Tsunekawa, M., Ishida, E., Kawai, K., Takahashi, T., Abe, N., Hiroyoshi, N., 2010. Reverse jig separation of shredded floating plastic - separation of polypropylene and high density polyethylene. Int. J. Miner. Process. 97, 96-99. https://doi.org/10.1016/j.minpro.2010.08.007.

Jeon, S., Tabelin, C.B., Takahashi, H., Park, I., Ito, M., Hiroyoshi, N., 2018a. Interference of coexisting copper and aluminum on the ammonium thiosulfate leaching of gold from printed circuit boards of waste mobile phones. Waste Manage. 81, 148-156. https://doi.org/10.1016/j.wasman.2018.09.041

Jeon, S., Ito, M., Tabelin, C.B., Pongsumrankul, R., Kitajima, N., Park, I., Hiroyoshi, N., 2018b. Gold recovery from shredder light fraction of E-waste recycling plant by flotation-ammonium thiosulfate leaching. Waste Manage. 77, 195-202. https://doi.org/10.1016/j.wasman.2018.04.039

Jeon, S., Ito, M., Tabelin, C.B., Pongsumrankul, R., Tanaka, S., Kitajima, N., Saito, A., Park, I., Hiroyoshi, N., 2019. A physical separation scheme to improve ammonium thiosulfate leaching of gold by separation of base metals in crushed mobile phones. Miner. Eng. 138, 168-177. https://doi.org/10.1016/j.mineng.2019.04.025

Kikuchi, R., Kukacka, J., Raschman, R., 2008. Grouping of mixed waste plastics according to chlorine content. Sep. Purif. Technol. 61, 75-81. https://doi.org/10.1016/j.seppur.2007.10.001.

Kuwayama, Y., Ito, M., Hiroyoshi, N., Tsunekawa, M., 2011. Jig separation of crushed automobile shredded residue and its evaluation by float and sink analysis. J. Mater. Cycles. Waste. Manag, 13, 240-246. https://doi.org/10.1007/s10163011-0008-y. 
MBE Coal\& Minerals Technology GMBH, 2014. BATAC \& ROM Jig jigging technology, http://www.mbecmt.com/fileadmin/user_upload/Download_Produktflyer/mbe_Jigging_e_RZ_ 120305.pdf (accessed 20 June 2018)

Ministry of the Environment of Japan, 2014. History and Current State of Waste Management in Japan. https://www.env.go.jp/en/recycle/smcs/attach/hcswm.pdf. (accessed 25 December 2017).

Plastic Waste Management Institute of Japan, 2018. Current status of production, disposal, recycling, and disposal of plastic products. http://www.pwmi.or.jp/pdf/panf2.pdf. (accessed 7 March 2019).

Phengsaart, T., Ito, M., Hamaya, N., Tabelin, C.B., Hiroyoshi, N., 2018. Improvement of jig efficiency by shape separation, and a novel method to estimate the separation efficiency of metal wires in crushed electronic wastes using bending behavior and "entanglement factor". Miner. Eng. 129, 54-62. https://doi.org/10.1016/j.mineng.2018.09.015.

Pita, F., Castilho, A., 2016. Influence of shape and size of the particles on jigging separation of plastics mixture. Waste. Manage. 48, 89-94. https://doi.org/10.1016/j.wasman.2015.10.034.

PlasticsEurope, 2018. Plastics - the Facts 2018. An Analysis of European Plastics Production, Demand and Waste Data, https://www.plasticseurope.org/application/files/6315/4510/9658/Plastics_the_f acts_2018_AF_web.pdf. (accessed 15 May 2019).

Statista, 2019. Global Plastic Production from 1950 to 2017 (In Million Metric Tons). https://www.statista.com/statistics/282732/global-production-of-plastics-since1950. (accessed 15 May 2019).

Tsunekawa, M., Naoi, B., Ogawa, S., Hori, K., Hiroyoshi, N., Ito, M., Hirajima, T., 2005. Jig separation of plastics from scrapped copy machines. Int. J. Miner. Process. 76, 67-74. https://doi.org/10.1016/j.minpro.2004.12.001.

Tsunekawa, M., Kobayashi, R., Hori, K., Okada, H., Abe, N., Hiroyoshi, N., Ito, M., 2012. Newly developed discharge device for jig separation of plastics to recover higher grade bottom layer product. International Journal of Mineral Processing, 114117, 27-29. https://doi.org/10.1016/j.minpro.2012.09.003.

Wills, B.A., Napier-Munn, T.J., 2006. Mineral Processing Technology, seventh ed. Pergamon press, Oxford. 